\title{
Effect of Sodium Chloride Gradients on Water Flux in Rat Descending Vasa Recta
}

Thomas L. Pallone

Division of Nephrology, The Milton S. Hershey Medical Center of the Pennsylvania State University, Hershey, Pennsylvania 17033

\begin{abstract}
In the hydropenic kidney, volume efflux from descending vasa recta (DVR) occurs despite an intracapillary oncotic pressure that exceeds hydraulic pressure. That finding has been attributed to small solute gradients which may provide an additional osmotic driving force favoring water transport from DVR plasma to the papillary interstitium. To test this hypothesis, axial gradients of $\mathrm{NaCl}$ and urea in the papilla were eliminated by administration of furosemide and saline. DVR were then blocked with paraffin and microperfused at $10 \mathrm{nl} / \mathrm{min}$ with a buffer containing albumin, fluorescein isothiocyanate labeled dextran (FITC-Dx), ${ }^{22} \mathrm{Na}$, and $\mathrm{NaCl}$ in a concentration of $\mathrm{O}$ (hypotonic to the interstitium), 161 (isotonic) or $322 \mathrm{mM}$ (hypertonic). Collectate was obtained from the perfused DVR by micropuncture and the collectate-to-perfusate ratios of FITCDx and ${ }^{22} \mathrm{Na}$ were measured. A mathematical model was employed to determine DVR permeability $\left(P_{s}\right)$ and reflection coefficient to $\mathrm{NaCl}\left(\sigma_{\mathrm{NaCl}}\right)$. The rate of transport of water from the DVR lumen to the papillary interstitium was $2.8 \pm 0.3\left(\mathbf{N}_{\mathrm{v}}\right.$ $=22),-0.19 \pm 0.4\left(N_{v}=15\right)$, and $-2.3 \pm 0.3 \mathrm{nl} / \mathrm{min}\left(N_{v}=21\right)$ (mean \pm SE) when perfusate $\mathrm{NaCl}$ was 0,161 , or $322 \mathrm{mM}$, respectively $\left(N_{v}=\right.$ number of DVR perfused). The collectate-toperfusate ${ }^{22} \mathrm{Na}$ concentration ratios were $0.34 \pm 0.04,0.36 \pm 0.04$ and $0.37 \pm 0.03$ for those groups, respectively. Based on these data, Ps is calculated to be $60.4 \times 10^{-5} \pm 4.0 \times 10^{-5} \mathrm{~cm} / \mathrm{s}$ and $\sigma_{\mathrm{NaCl}}<0.05$. The results of this study confirm that transcapillary $\mathrm{NaCl}$ concentrations gradients induce water movement across the wall of the DVR. (J. Clin. Invest. 1991. 87:12-19.) Key words: descending vasa recta $\bullet$ sodium chloride $\bullet$ urinary concentration - rat - micropuncture - microperfusion • in vivo
\end{abstract}

\section{Introduction}

The role of the renal medullary microcirculation in the maintenance of corticomedullary solute gradients and the control of solute and water excretion is incompletely understood. Models of the urinary concentrating mechanism frequently neglect the role of the microcirculation by assuming that descending vasa recta (DVR) ${ }^{1}$, ascending vasa recta (AVR), and the medullary

Address reprint requests to T. L. Pallone, Division of Nephrology, PO Box 850, The Milton S. Hershey Medical Center, Hershey, PA 17033.

Received for publication 19 June 1990 and in revised form 5 September 1990.

1. Abbreviations used in this paper: AVR, ascending vasa recta; DVR, descending vasa recta; VR, vasa recta.

J. Clin. Invest.

(c) The American Society for Clinical Investigation, Inc.

0021-9738/91/01/0012/08 $\$ 2.00$

Volume 87, January 1991, 12-19 interstitium are a single compartment that is in perfect equilibrium (1). This assumption circumvents the need to solve the transport and conservation equations that define tubular-vascular relationships but results in an inability to obtain predictions of the effects of perturbations of vasa recta blood flow on urinary concentration and salt or water excretion.

In contrast to a simplified view of microvascular transport, it has been demonstrated that the phenomena that govern the equilibration of DVR plasma with the medullary interstitium are complex. As blood descends from the corticomedullary junction toward the papillary tip, an increasingly hypertonic interstitium is encountered. The lag in equilibration of DVR plasma with the medullary interstitium results in the generation of transcapillary gradients of $\mathrm{NaCl}$ and urea as those solutes diffuse into the DVR lumen (2). It has been demonstrated that plasma protein is concentrated as blood flows from the papillary base toward the tip in the DVR. This has been taken to imply water removal from those capillaries (3). DVR plasma oncotic pressure exceeds hydraulic pressure so that transport of water from DVR plasma to the papillary interstitium occurs despite the existence of intracapillary Starling forces that favor volume uptake (3). Sanjana et al. proposed that transcapillary "small solute" gradients provide a driving force of sufficient magnitude to oppose plasma oncotic pressure and promote the observed volume efflux from the DVR. Transcapillary volume flux across the DVR wall, Jv, can be described by $(3,4)$.

$J_{v}=L_{\mathrm{p}}\left\{\Delta P-\sigma_{\mathrm{p}} \Delta \Pi_{\mathrm{p}}-\sigma_{\mathrm{ss}} \Delta \Pi_{\mathrm{ss}}\right\}$,

where $L_{\mathrm{p}}$ is the hydraulic conductivity of the DVR wall, $\sigma_{\mathrm{p}}$ is the reflection coefficient of the DVR wall to plasma proteins, $\Delta P$ is the transcapillary hydraulic pressure difference, $\Delta \Pi_{\mathrm{p}}$ and $\Delta \Pi_{\mathrm{ss}}$ are transcapillary hydraulic and osmotic pressure differences due to proteins and small solutes, respectively. In order for small solute osmotic pressure to affect water flux, the reflection coefficient of the DVR wall to small solutes $\left(\sigma_{\mathrm{ss}}\right)$ in Eq. 1 must be nonzero (3). To be precise, $\sigma_{\mathrm{ss}}$ may refer to the reflection coefficient of the DVR wall to $\mathrm{NaCl}\left(\sigma_{\mathrm{NaCl}}\right)$, urea $\left(\sigma_{\text {urea }}\right)$ or both. Curry et al. have demonstrated that the reflection coefficient of continuous capillaries of the frog mesentery to these solutes is $\sim 0.07(5)$. We have shown that the elimination of axial gradients of $\mathrm{NaCl}$ and urea in the papilla results in abatement of volume efflux from DVR (6). Those results support but do not prove the small solute hypothesis. They also fail to define the magnitude of $\sigma_{\mathrm{NaCl}}$ or $\sigma_{\mathrm{urea}}$, parameters which must eventually be known before models of the urinary concentrating mechanism can capture tubularvascular relationships in the renal medulla.

In a recent communication, we described a method for performing free flow microperfusion of DVR in rats undergoing furosemide and saline diuresis (7). Under these conditions, corticomedullary gradients of $\mathrm{NaCl}$ and urea are eliminated so that concentrations of these solutes in the plasma of nonperfused vasa recta should reflect that of the medullary interstitium $(6,7)$. In the present study, DVR have been perfused with 
buffers containing $\mathrm{NaCl}$ in a concentration less than, equal to, or greater than that of the papillary interstitium. This was performed to determine whether transcapillary gradients of $\mathrm{NaCl}$ can promote transcapillary volume movement, providing a definitive test of the small solute hypothesis and permitting an estimate of $\sigma_{\mathrm{NaCl}}$ to be obtained.

\section{Methods}

Female Munich-Wistar rats weighing 70-120 g were obtained from Harlan Sprague-Dawley. The animals were allowed free access to food and water until the time of the experiment. Anesthesia was obtained by an intraperitoneal injection of thiopental, $50 \mathrm{mg} / \mathrm{kg}$ body wt. The rats were placed on a heated table and body temperature was maintained between 36 and $38^{\circ} \mathrm{C}$ as measured by rectal probe. For infusions and bolus injections, the jugular vein was cannulated with PE-50 tubing that had been tapered by pulling over a flame. A tracheostomy was performed, the left femoral artery cannulated for blood pressure monitoring, and a bladder catheter inserted to measure urine flow from the right kidney.

A subcostal incision was made to expose the left kidney. The suprarenal artery and vein were ligated, and the adrenal gland cut away from the kidney using microscissors. The animal was repositioned onto its right side, and the left kidney freed from its attachments to the abdominal wall. The kidney was then gently placed into a lucite cup exposing its dorsal aspect. Cotton soaked with $1.5 \%$ agar was used to surround and immobilize the kidney. The ureter was then completely excised to expose 2-3 mm of extrarenal papilla. The papilla was tangentially illuminated with a fiber optic light guide. Mineral oil, warmed to $37^{\circ} \mathrm{C}$, was used to superfuse the papilla and prevent tissue dehydration. After surgery, a 30-min equilibration period was permitted to elapse before micropuncture or microperfusion were performed.

\section{Experimental Design}

The animals were divided into three groups according to the technique used to study them. In Group I, micropuncture of vasa recta (VR) was performed at the base and tip of the exposed papilla to obtain plasma for measurement of osmolality and urea concentrations. Group I experiments provided measurement of intracapillary solute concentrations which, during furosemide and saline diuresis, presumably reflect those of the papillary interstitium. In Group II, individual DVR were punctured twice, once at the papillary tip for microperfusion and a second time near the base to collect samples for determination of osmolality and ${ }^{22} \mathrm{Na}$ concentration. Group II experiments were performed to verify that the diffusion of ${ }^{22} \mathrm{Na}$ into the medullary interstitium reflected the osmotic equilibration of the perfusate. In Group III, individual DVR were also punctured twice, once at the tip for microperfusion and a second time near the base for sample collection. Transcapillary volume and ${ }^{22} \mathrm{Na}$ flux were determined from these experiments. Group III experiments were performed to determine the effect of transcapillary $\mathrm{NaCl}$ concentration gradients on transcapillary volume flux.

All animals received a bolus injection of $0.14 \mathrm{mg} / 100 \mathrm{~g} \mathrm{BW}$ of furosemide in a volume of $0.2 \mathrm{ml} / 100 \mathrm{~g} \mathrm{BW}$ of saline at the time of the insertion of the jugular venous catheter. This was followed by $2.3 \mu \mathrm{m} /$ $\mathrm{min} / 100 \mathrm{~g} \mathrm{BW}$ of furosemide in $60 \mu \mathrm{l} / \mathrm{min}$ per $100 \mathrm{~g} \mathrm{BW}$ of saline. After the completion of the postsurgical equilibration period, animals were given $200 \mathrm{U} / 100 \mathrm{~g} \mathrm{BW}$ of heparin $(1,000 \mathrm{U} / \mathrm{ml})$ to prevent coagulation of vasa recta blood.

The surgical preparation and furosemide infusion protocol are identical to that previously described $(6,7)$.

Group I $(n=6)$. DVR were punctured at the base and tip of the exposed papilla for plasma collections. Siliconized, sharpened micropipettes with outside tip diameters of $12 \mu \mathrm{m}$ were used. The pipettes were filled with water-equilibrated mineral oil stained with sudan black. Upon puncture of a vas rectum, a droplet of oil was injected to verify location and the direction of flow and to rule out fistula formation with other medullary structures. Gentle suction was transiently applied after which blood flowed into the pipette spontaneously. The order of punctures was random. The position of each puncture was recorded by measuring its distance from the papillary tip with a calibrated eyepiece micrometer. At the end of the experiment, an arterial blood sample was drawn for determination of systemic plasma osmolality. The method used to separate plasma from red blood cells (RBCs) was identical to that previously described (8).

Groups II-322, and II-O ( $n=6$, each subgroup). The technique employed to microperfuse DVR is a modification of the technique described by Marsh and Segel (9) and has been described in detail (7). Briefly, DVR were chosen for microperfusion by observing them on the surface of the papilla. DVR were isolated for microperfusion by placing a paraffin block as near to the papillary tip as technically possible (10). After injection of the paraffin wax, RBCs in the vessel were observed to be sure that blood flow became completely stagnant, ruling out upstream branch points (7). On rare occasions, a visible branch point was blocked by a second paraffin injection.

After placement of the paraffin block, DVR were cannulated just above the block and perfused retrograde toward the papillary base. Individual DVR were perfused with buffer containing $5 \mathrm{mg} / \mathrm{ml}$ of 2 $\times 10^{6} \mathrm{~mol}$ wt dextran labeled with fluorescein isothiocyanate (FITCDx) (Sigma Chemical Co., St. Louis, MO) and a negligible volume fraction of suspended $1.1-\mu \mathrm{m}$. latex beads (Sigma Chemical Co.). The buffer contained $\mathrm{NaCl}$ in a concentration of $322 \mathrm{mM}$ (group II-322) or $0 \mathrm{mM}$ (group II-0) to be hypertonic or hypotonic to the medullary interstitium, respectively. A complete description of the perfusate composition is provided below. In group II-322, where the lumen-to-interstitium concentration gradient of $\mathrm{NaCl}$ favored diffusive efflux, tracer amounts of ${ }^{22} \mathrm{Na}$ (New England Nuclear, Boston, MA) were also added to the perfusate so that osmolar equilibration of the perfusate with the papillary interstitium could be compared to the equilibration of ${ }^{22} \mathrm{Na}$. The ratio of the concentration of ${ }^{22} \mathrm{Na}$ in the collectate $\left(C_{\mathrm{c}}^{*}\right)$ to that in the perfusate $\left(C_{\mathrm{o}}^{*}\right)$ is

Na ratio $=\frac{C_{\mathrm{c}}{ }^{*}}{C_{\mathrm{o}}{ }^{*}}$

If the equilibration of the isotope with the papillary interstitium reflects the equilibration of $\mathrm{NaCl}$, the $\mathrm{Na}$ ratio should be equal to the osmolar ratio defined by

osmolar ratio $=\frac{\text { Osm }_{c}-\text { Osm }_{i}}{\text { Osm }_{\mathrm{o}}-\mathrm{Osm}_{\mathrm{i}}}$,

where $\mathrm{Osm}_{c}, \mathrm{Osm}_{\mathrm{o}}$, and $\mathrm{Osm}_{\mathrm{i}}$ are the osmolality of the collectate, perfusate, and papillary interstitium, respectively.

Microperfusion was performed using pipettes with outside diameters of $10-12 \mu \mathrm{m}$. These pipettes were filled retrograde by aspirating the perfusate from a droplet under mineral oil. The remaining length of the pipette was loaded with mineral oil stained with sudan black by injecting from the rear of the pipette with a syringe and 26-gauge needle. In this fashion, all air bubbles were eliminated from the pipette. Microperfusion was driven at a rate of $10 \mathrm{nl} / \mathrm{min}$ using a model A 1400 hydraulic NanoPump (World Precision Instruments, Inc., Worchester, MA). The pump was calibrated using the sensitive fluorescent FITC-Dx microassay described previously (7) and below.

DVR were punctured with the perfusion pipette at a low angle. The flow of buffer in the perfusion pipette was visible due to the presence of the latex beads suspended in the buffer. This helped to verify that perfusion was steady and to assure against fistula formation with other papillary structures or leakage at the perfusion site. Perfusion continued for a few moments after which a collection pipette was inserted, bevel down, into the perfused vessel as far downstream from the perfusion site as technically possible. The tips of the collection pipettes were gradually tapered and beveled to an outside diameter of $10 \mu \mathrm{m}$. These pipettes were siliconized and preloaded with water-equilibrated mineral oil stained with sudan black. Upon puncture with the collection pipette, a small drop of mineral oil was injected to verify location. Once the perfusate flow was again stable, gentle suction was applied to initi- 
ate sample withdrawal. Collection was maintained at a rate that was slower than the rate of perfusate flow at the collection site. This often required a small positive pressure to be applied to the collection pipette. The distance from the perfusion to collection sites was determined with a calibrated ocular micrometer.

Group III-161 $(n=10), I I I-322(n=12)$, and III-O $(n=12)$. In a manner identical to that described above for group III, microperfusion of DVR segments was performed at $10 \mathrm{nl} / \mathrm{min}$ after the placement of a paraffin block. The perfusate buffer was identical in composition, containing FITC-labeled dextran, latex beads and ${ }^{22} \mathrm{Na}$. The concentration of $\mathrm{NaCl}$ was either 161,322 , or $0 \mathrm{mM}$ as defined by the above group subheadings. DVR diameters were measured for group III-161 only. After preparing the papillae of these animals, the preparation was transferred on the operating table onto a specially constructed acrylic stage under a Nikon MM-11 industrial microscope. The papilla was observed under a $40 \times$ objective using a calibrated eyepiece micrometer. The diameters of DVR to be microperfused were measured. The preparation was subsequently transferred back and further experimentation performed under a stereomicroscope.

\section{Perfusate buffer}

The concentration of urea was chosen to match the average of base and tip DVR plasma samples in group I rats (see Results). The potassium concentration was set at $9 \mathrm{mM}$ as previously described $(6,7)$. The composition of the perfusate buffer was $\mathrm{NaH}_{2} \mathrm{PO}_{4} 0.29 \mathrm{mM} ; \mathrm{Na}_{2} \mathrm{HPO}_{4}$ $1.71 \mathrm{mM} ; \mathrm{KCl} 9.0 \mathrm{mM} ; \mathrm{MgCl}_{2} 1.0 \mathrm{mM} ; \mathrm{CaCl}_{2} 1.0 \mathrm{mM}$; urea $50 \mathrm{mM}$; Hepes $5 \mathrm{mM}$, BSA $5 \mathrm{~g} / 100 \mathrm{ml}, \mathrm{pH}$ 7.4. $\mathrm{NaCl}$ was also included in the perfusate buffer in concentrations specified (in millimolar) as the subheading of each group.

\section{Analytical methods}

Microanalysis of FITC-Dx. A detailed description of this method has been provided (7). Briefly, fluorescence was measured using a photon counting microscope detection assembly (model D104B, Photon Technology International, South Brunswick, NJ) placed on the sideport of an inverted microscope (Nikon Diaphot, Garden City, NY). The output of the photomultiplier tube (Hamamatsu type R 1527, Bridgewater, NJ) was monitored with a multichannel scaling card (ACE-MCS, EG\&G Ortec, Oak Ridge, TN) in a model ES/12 computer (HewlettPackard Co., Palo Alto, CA). The microscope is equipped for transmitted or epifluorescent illumination using an HBO 100-W mercury lamp. Visualization and measurement of FITC was accomplished by use of a Nikon B-2A filter block which contains a 510-nm dichroic mirror, 450-490-nm bandpass excitation filter and $>520-\mathrm{nm}$ barrier filter.

Samples of perfusate, collectate, and perfusate free of FITC-Dx (assayed for background measurements) were placed into a siliconized petri dish under water-equilibrated mineral oil. $5 \mu$ l of PBS was loaded into 50- $\mu \mathrm{l}$ microcaps that had been cut in half. Using volumetric constriction pipettes prepared on a microforge (Stoelting Co., Chicago, IL), $\sim 1 \mathrm{nl}$ volumes of samples were dispensed into the $5 \mu \mathrm{l}$ of PBS. The ends of the microcap were flame-sealed and centrifuged back and forth for mixing. The sealed microcaps served as cuvettes for subsequent measurement of fluorescence. Background fluorescence was subtracted from that measured in the perfusate and collectate to determine the final perfusate and collectate fluorescence, $C_{o}$ and $C_{1}$, respectively. The rate of volume efflux ( $Q_{v}$, nanoliters per minute) from the capillary to the papillary interstitium was determined from

$Q_{v}=Q_{0}\left\{1-\frac{C_{0}}{C_{1}}\right\}$

where $Q_{0}$ is the rate of capillary perfusion $(10 \mathrm{nl} / \mathrm{min})$. The linearity and accuracy of this assay as well as the binding of FITC to the dextran molecule have been verified (7). FITC-Dx concentration was always measured immediately after each experiment in samples briefly stored under water-equilibrated mineral oil. Where required, the cuvettes were also counted for ${ }^{22} \mathrm{Na}$ in a gamma counter (Beckman Instruments, Inc., Fullerton, CA).
Other assays. Vasa recta plasma urea concentrations were determined in duplicate by the microcolorimetric method described by Vurek and Knepper (11). Sample handling and the microassays were performed on the day of the experiment in a manner identical to that previously described $(6,8)$. Osmolalities in microsamples were determined by the Ramsey-Brown microfreezing point technique (12).

Statistical analysis. Experimental results are reported as mean \pm SE. Statistical comparisons employed paired or unpaired student $t$-tests as appropriate. For group III comparisons, ANOVA was employed to test for significance.

Mathematical model. To estimate the value of $\sigma_{\mathrm{NaC}}$ for the DVR and the diffusive permeability of the DVR to $\mathrm{NaCl}\left(\boldsymbol{P}_{\mathrm{s}}\right)$, the following model was applied to analyze transport events in the microperfused capillaries. The change in flow rate $(Q)$ along the length of the perfused capillary is given by

$\frac{\mathrm{d} Q}{\mathrm{~d} x}=-J_{v} \pi D$,

where $J_{v}$ is the rate of transmembrane volume flux and $D$ is capillary diameter. The rate of loss of $\mathrm{NaCl}$ to the papillary interstitium is described by

$\frac{\mathrm{d}}{\mathrm{d} x}\left(Q C_{\mathrm{s}}\right)=-J_{\mathrm{s}} \pi D$,

where $C_{\mathrm{s}}$ is $\mathrm{NaCl}$ concentration and $J_{\mathrm{s}}$ is the transmembrane flux of $\mathrm{NaCl}$. The loss of tracer ${ }^{22} \mathrm{Na}$ to the interstitium is given by

$\frac{\mathrm{d}}{\mathrm{d} x}\left(Q C_{\mathrm{s}}^{*}\right)=-J_{\mathrm{s}}^{*} \pi D$,

where $C_{\mathrm{s}}{ }^{*}$ is ${ }^{22} \mathrm{Na}$ concentration and $J_{\mathrm{s}}{ }^{*}$ is transmembrane flux of ${ }^{22} \mathrm{Na}$. $J_{\mathrm{v}}$ is given by $(2,4)$,

$J_{v}=L_{\mathrm{p}}\left\{\left(P_{\mathrm{c}}-\Pi_{\mathrm{c}}\right)-1.86 \sigma_{\mathrm{NaC}} R T\left(\Delta C_{\mathrm{s}}\right)-\gamma\right\}$,

where $L_{\mathrm{p}}$ is DVR hydraulic conductivity, $P_{\mathrm{c}}$ and $\Pi_{\mathrm{c}}$ are intracapillary hydraulic and oncotic pressure, respectively, $R$ is the universal gas constant, and $T$ is absolute temperature. $\gamma$ is the sum of hydraulic and oncotic pressure in the papillary interstitium. The factor 1.86 accounts for the activity of sodium and chloride ions in solution. Eq. 8 assumes a value of unity for the reflection coefficient of the DVR for albumin.

$\Pi_{c}$ is given by reference 13 :

$\Pi_{\mathrm{c}}=2.8 C_{\mathrm{a}}+0.18\left(C_{\mathrm{a}}\right)^{2}+0.012\left(C_{\mathrm{a}}\right)^{3}$,

where $C_{\mathrm{a}}$ is albumin concentration. It is assumed that little albumin escapes across the DVR wall so that the product of intracapillary flow rate and albumin concentration is constant, i.e., $C_{\mathrm{ao}} \cdot Q_{\mathrm{o}}=C_{\mathrm{a}} \cdot Q$. The subscript $o$ refers to the value of the variable at the tip of the perfusion pipette.

Transcapillary flux of $\mathrm{NaCl}$ is defined by reference 14 :

$J_{\mathrm{s}}=J_{\mathrm{v}}\left(1-\sigma_{\mathrm{NaCl}}\right) \frac{C_{\mathrm{s}}-C_{\mathrm{si}} \mathrm{e}^{-\beta}}{1-e^{-\beta}}$,

where $C_{\mathrm{si}}$ is the $\mathrm{NaCl}$ concentration of the papillary interstitium. Transcapillary volume flux of ${ }^{22} \mathrm{Na}$ is given by

$J_{s}^{*}=J_{v}\left(1-\sigma_{\mathrm{NaCl}}\right) \frac{C_{\mathrm{s}}^{*}}{1-e^{-\beta}}$,

where the concentration of ${ }^{22} \mathrm{Na}$ in the papillary interstitium is assumed to be zero. $\beta$ is the Peclet number,

$\beta=\frac{J_{v}\left(1-\sigma_{\mathrm{NaCl}}\right)}{P_{\mathrm{s}}}$,

where $P_{s}$ is the diffusive permeability of the DVR wall for $\mathrm{NaCl}$. The reflection coefficient and diffusive permeability of the capillary wall for ${ }^{23} \mathrm{NaCl}$ and ${ }^{22} \mathrm{NaCl}$ is assumed to be identical. 
When $J_{v}=0$, Eqs. $6-11$ can be solved directly to yield

$P_{\mathrm{s}}=\left(\frac{Q_{\mathrm{o}}}{\pi D L}\right) \ln \left(\frac{C_{\mathrm{so}}^{*}}{C_{\mathrm{s}}^{*}}\right)$,

where $L$ is the length of the perfused capillary segement.

To determine the values of $\sigma_{\mathrm{NaC}}$ and $P_{3}$ for experiments in which $J_{\mathrm{v}}$ is nonzero, we numerically integrated Eqs. 5-12 along the length of the capillary to obtain a prediction of $F_{\mathrm{v}}=Q / Q_{0}$ and $F_{\mathrm{s}}=C_{\mathrm{s}}{ }^{*} / C_{\mathrm{s}}{ }^{*}$. The value of $\sigma_{\mathrm{NaC}}$ employed by the model was iteratively adjusted until the predicted value of $F_{\mathrm{v}}$ matched the experimental value. The value of $P_{\mathrm{s}}$ was also iteratively adjusted until the predicted value of $F_{\mathrm{s}}$ matched that measured experimentally. Convergence was accepted when both $F_{\mathrm{v}}$ and $F_{\mathrm{s}}$ agreed with their experimental values within a factor of 1 $\times 10^{-3}$. Equations were integrated numerically on a Hewlet-Packard Vectra RS/20 computer by the method of Gear (15) using a Microsoft Fortran compiler.

\section{Results}

Whole animal data. The number of animals used (NA) and vessels perfused (NV) in each group as well as the mean body weight, mean arterial pressure, and urine flow rate from the right kidney are listed in Table I. The diuresis induced by the saline and furosemide infusion protocol is similar in magnitude to that of our prior studies $(6,7)$.

Corticomedullary gradients. Osmolality and urea concentration measurements obtained at the DVR base and tip and the locations of those punctures are shown for group I in Table II. As intended, furosemide eliminated corticomedullary gradients. These data are comparable with those previously obtained $(6,7)$.

Osmolar equilibration. Collectate osmolality (ordinate) is shown as a function of the length of the perfused capillary segment (abscissa) in the upper panel of Fig. 1. Solid circles depict the data for group II-322 and open circles for group II-0. The dashed line is drawn at the papillary interstitial osmolality of $375 \mathrm{mOsm} / \mathrm{kg} \mathrm{H} \mathrm{H}_{2} \mathrm{O}$ obtained from micropuncture data in group I (Table II). The rapid equilibration of microperfused DVR with the papillary interstitium is apparent. A comparison of the osmolar ratio, Eq. 3 (solid circles) and ${ }^{22} \mathrm{Na}$ ratio, Eq. 2 (open circles) is depicted as a function of length in the lower panel of Fig. 1 for group II-322. There was some tendency for the ${ }^{22} \mathrm{Na}$ ratio $(0.27 \pm 0.06$, mean $\pm \mathrm{SE})$ to exceed the osmolar ratio $(0.22 \pm 0.08)$ but this was not significant. These data lend support to the use of ${ }^{22} \mathrm{Na}$ concentration measurement to re-

Table I. Whole Animal Data

\begin{tabular}{lccccc}
\hline Group & NA & NV & Weight & MAP & Urine flow \\
\hline & & & $g$ & $m m H g$ & $\mu l / m i n$ \\
I & 6 & - & $101 \pm 5$ & $121 \pm 6$ & $33 \pm 3$ \\
II-322 & 6 & 11 & $100 \pm 4$ & $119 \pm 13$ & $37 \pm 3$ \\
II-0 & 6 & 13 & $89 \pm 2$ & $114 \pm 9$ & $33 \pm 3$ \\
III-161 & 10 & 15 & $80 \pm 2$ & $117 \pm 4$ & $36 \pm 3$ \\
III-322 & 12 & 21 & $86 \pm 2$ & $123 \pm 8$ & $33 \pm 3$ \\
III-0 & 12 & 22 & $88 \pm 2$ & $118 \pm 4$ & $33 \pm 4$ \\
\end{tabular}

Values are reported as mean \pm SE. MAP is mean arterial pressure, NA is the number of animals studied, and NV is the number of capillaries perfused. The values after the group designations $(0,161,322)$ refer to the perfusate sodium concentration.
Table II. Osmolality and Urea Concentrations in DVR Plasma at the Base and Tip of the Papilla, Group I $(n=6)$

\begin{tabular}{|c|c|c|c|}
\hline & DVR-base & $P$ & DVR-tip \\
\hline $\begin{array}{l}\text { Osmolality } \\
\quad\left(\mathrm{mosmol} / \mathrm{kg} \mathrm{H} \mathrm{H}_{2} \mathrm{O}\right)\end{array}$ & $375 \pm 11$ & NS & $374 \pm 9$ \\
\hline [Urea] & & & \\
\hline$(m M)$ & $48 \pm 5$ & NS & $53 \pm 6$ \\
\hline $\begin{array}{l}{[\mathrm{Na}+\mathrm{K}]} \\
\quad(m E q / \text { liter })\end{array}$ & $177 \pm 5$ & NS & $174 \pm 4$ \\
\hline $\begin{array}{c}\text { Distance } \\
(\mathrm{mm})\end{array}$ & $2.1 \pm 0.07$ & & $0.6 \pm 0.04$ \\
\hline
\end{tabular}

Values are reported as mean $\pm \mathrm{SE}$. The locations of punctures are reported as distance in millimeters from the papillary tip. The sum of $\mathrm{Na}$ and $\mathrm{K}$ concentrations was determined from $[\mathrm{Na}+\mathrm{K}]=$ (osmolality - urea)/1.86 (8).

flect the equilibration of $\mathrm{NaCl}$ in the perfusate with the interstitium.

The average capillary segment length, diameter (group III161 only), and collectate-to-perfusate ratios of FITC-Dx and ${ }^{22} \mathrm{Na}$ are shown for group III in Table III. Fig. 2 shows the collectate-to-perfusate ratios of FITC-Dx (open circles) and
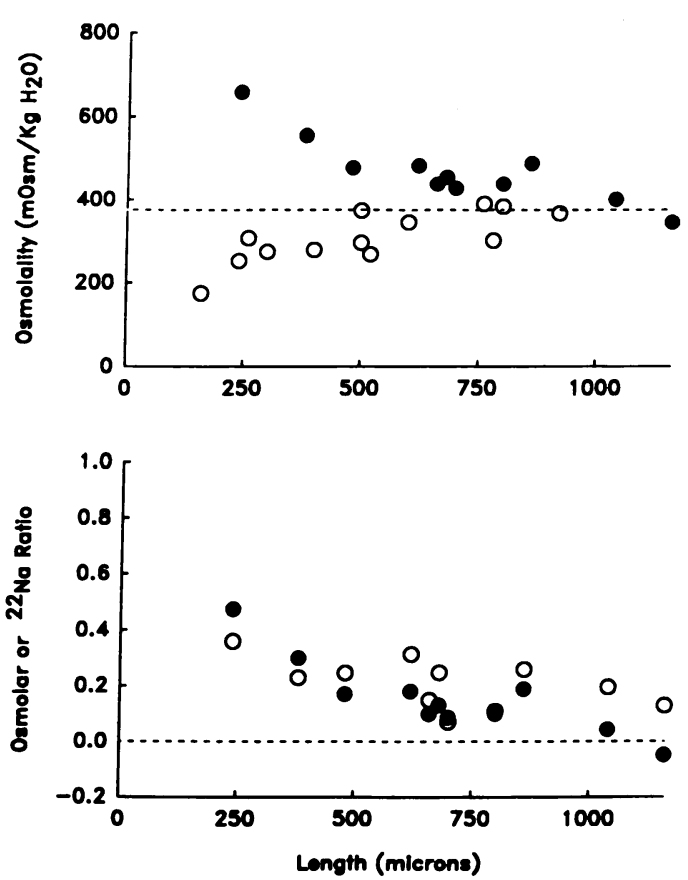

Figure 1. Perfusate osmolar equilibration with the papillary interstitium. (Top) Collectate osmolality (ordinate) is plotted as a function of the length of the DVR segment perfused. Solid circles represent measurements from DVR perfused with buffer containing $\mathrm{NaCl}$ at a concentration of $322 \mathrm{mM}$, and open circles represent measurements from DVR perfused with buffer containing $\mathrm{NaCl}$ at a concentration of $0 \mathrm{mM}$. The dashed line is drawn at $375 \mathrm{mosmol} / \mathrm{kg}$ $\mathrm{H}_{2} \mathrm{O}$ which is representative of the papillary interstitium during furosemide diuresis. (Bottom) The osmolar ratio (Eq. 3, solid circles) or ${ }^{22} \mathrm{Na}$ ratio (Eq. 2, open circles) are plotted as a function of perfused segment length. The dashed line is drawn at zero, representative of complete perfusate-interstitial equilibration. 
Table III. Descending Vasa Recta Perfusions, Group III

\begin{tabular}{lccc}
\hline & Group III-161 & Group III-322 & Group III-0 \\
\hline Length $(\mu \mathrm{m})$ & $578 \pm 60$ & $547 \pm 52$ & $543 \pm 46$ \\
Diameter $(\mu \mathrm{m})$ & $17.5 \pm 0.6$ & - & - \\
Ratio FITC-Dx & $1.0 \pm 0.03$ & $0.82 \pm 0.02^{*}$ & $1.43 \pm 0.04^{*}$ \\
Ratio ${ }^{22} \mathrm{Na}$ & $0.36 \pm 0.04$ & $0.37 \pm 0.03$ & $0.34 \pm 0.04$ \\
$Q_{\mathrm{v}}(\mathrm{nl} / \mathrm{min})$ & $-0.19 \pm 0.35$ & $-2.3 \pm 0.3^{*}$ & $2.8 \pm 0.3^{*}$
\end{tabular}

Values are reported as mean \pm SE. Values after the Group III designation $(0,161,322)$ refer to the perfusate $\mathrm{NaCl}$ concentration. Length refers to the length of the perfused capillary segment. Ratio refers to the collectate-to-perfusate ratio of FITC-Dx or ${ }^{22} \mathrm{Na}$. $Q_{\mathrm{v}}$ is the rate of volume reabsorption from the capillary lumen to the papillary interstitium. The perfusion rate was $10 \mathrm{nl} / \mathrm{min} .{ }^{*} P<0.01$ vs. group III-161.

${ }^{22} \mathrm{Na}$ concentration ( solid circles) as a function of the length of the perfused DVR segment for the 15 microvessel perfusions in group III-161. The exponential equilibration of ${ }^{22} \mathrm{Na}$ with the papillary interstitium is apparent. The average rate of transport of water from the DVR lumen to the papillary interstitium in group III-161 is calculated from the FITC-Dx volume marker ratio and Eq. 4 to be $-0.19 \pm 0.35 \mathrm{nl} / \mathrm{min}$, a value that is not significantly different from zero. This result is similar to that previously obtained for DVR perfusions with bicarbonate buffer containing albumin at a concentration of $5 \mathrm{~g} / \mathrm{dl}$ (7). Because $J_{v}=0$ for group III-161, Eq. 13 can be applied to the data to calculate the diffusive permeability of the DVR to $\mathrm{NaCl}$ $\left(P_{\mathrm{s}}\right)$. A value of $60.4 \times 10^{-5} \pm 4.0 \times 10^{-5} \mathrm{~cm} / \mathrm{s}$ is obtained. The solid curve in Fig. 2 is the prediction of the collectate-to-perfusate ${ }^{22} \mathrm{Na}$ concentration ratio for this value of $P_{\mathrm{s}}$. Fig. 3 shows the collectate-to-perfusate ${ }^{22} \mathrm{Na}$ concentration ratio (ordinate) as a function of the microvessel length (abscissa) for groups II-322 and III-322 (solid circles) and group III-0 (open circles). Because $J_{\mathrm{v}}$ is nonzero for these data points, estimation of $P_{\mathrm{s}}$ requires the use of a more complex model (see below).

Transmembrane volume flux. As expected, based on the assumption that the reflection coefficient of the DVR wall to $\mathrm{NaCl}$ is nonzero $(2,3,6)$, transmembrane volume flux $\left(J_{\mathrm{v}}\right)$ in the case of groups III- 0 and III-322 is nonzero. Of the $10 \mathrm{nl} / \mathrm{min}$ infused into individual DVR, $2.8 \pm 0.3 \mathrm{nl} / \mathrm{min}$ was transported

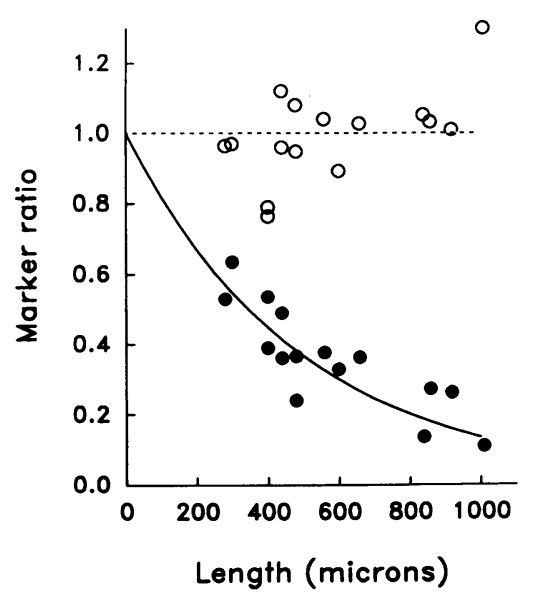

Figure 2. Collectate-toperfusate ratios of FITC-Dx or ${ }^{22} \mathrm{Na}$. The collectate-to-perfusate ratios of the FITClabeled dextran volume marker (open circles) or ${ }^{22} \mathrm{Na}$ (solid circles) are plotted as a function of the length of the perfused DVR segment for group III-161. The dashed line is drawn at unity. The solid curve represents the model predictions for a sodium permeability $\left(P_{\mathrm{s}}\right)$ of $60.4 \times 10^{-5} \mathrm{~cm} / \mathrm{s}$.

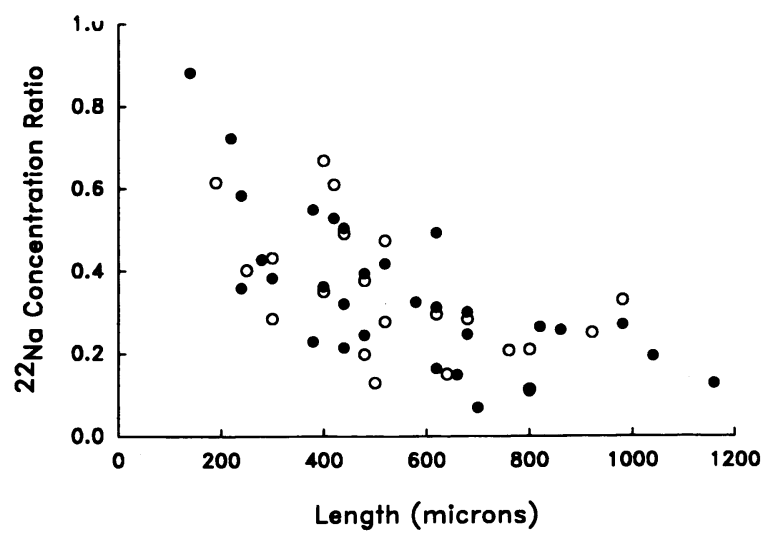

Figure 3. Collectate-to-perfusate ratio of ${ }^{22} \mathrm{Na}$. The collectate-toperfusate ratio of ${ }^{22} \mathrm{Na}$ concentration (ordinate) is plotted as a function of the length of the perfused DVR segment for groups III-322 (solid circles) and III-0 (open circles).

into the papillary interstitium when perfusate $[\mathrm{NaCl}]=0 \mathrm{mM}$ and $-2.3 \pm 0.3 \mathrm{nl} / \mathrm{min}$ was reabsorbed from the interstitium when perfusate $[\mathrm{NaCl}]=322 \mathrm{mM}$ (groups III-0 and III-322, Table III). Individual data for groups III-0 (solid circles) and III-322 (open circles) are shown in the left panel of Fig. 4 where $Q_{\text {v }}$ is plotted as a function of the perfused DVR segment length. These data provide the first definitive proof that transcapillary $\mathrm{NaCl}$ concentration gradients can produce osmotic water movement across the wall of the descending vasa recta.

Parameter estimations $\left(P_{s}\right.$ and $\left.\sigma_{\mathrm{NaC}}\right)$. In order to estimate the diffusive permeability of the DVR wall to $\mathrm{NaCl}$ and the reflection coefficient of the DVR wall for $\mathrm{NaCl}$ from group III data, the mathematical model outlined in Methods must be numerically integrated. When one provides values for DVR
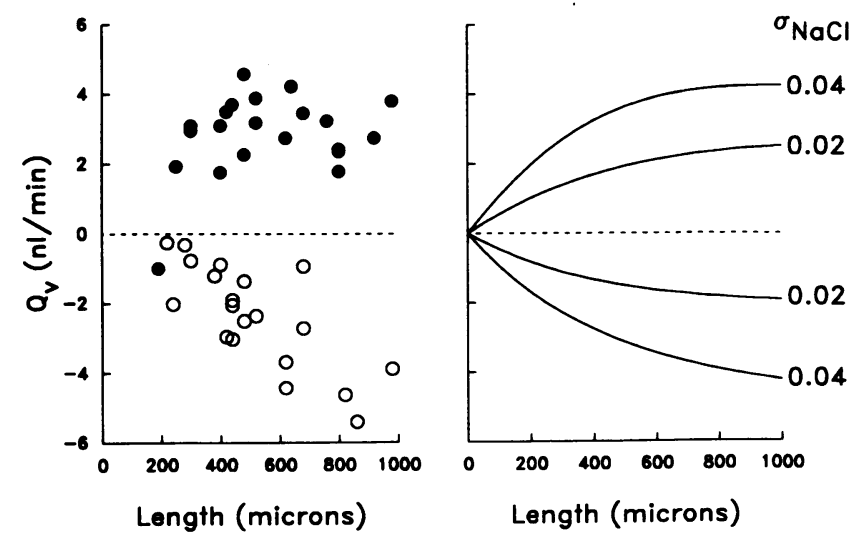

Figure 4. Transport of water into the medullary interstitium. (Left) $Q_{v}$, the rate of water transport from the perfused DVR lumen to the papillary interstitium expressed in nanoliters per minute, is plotted as a function of the length of the perfused DVR segment for group III-0 (solid circles) and III-322 (open circles). Positive values of $Q_{\mathrm{v}}$ imply filtration and negative values, volume uptake. (Right) Model predictions of the magnitude of $Q_{\mathrm{v}}$ as a function of DVR segment length for $\mathrm{DVR} \mathrm{NaCl}$ reflection coefficients, $\sigma_{\mathrm{NaCl}}$, of 0.02 and 0.04 . Computer simulations assume $L_{\mathrm{p}}=1.4 \times 10^{-6} \mathrm{~cm} /(\mathrm{s}-\mathrm{mmHg})$ and $\gamma=-7 \mathrm{mmHg}$. Perfusate $\mathrm{NaCl}$ concentration is either $0 \mathrm{mM}$ (upper curves) or $322 \mathrm{mM}$ (lower curves). Papillary $\mathrm{NaCl}$ concentration is assumed to be $161 \mathrm{mM}$. 
length and diameter as well as the measured FITC-Dx and ${ }^{22} \mathrm{Na}$ concentration ratio the model calculates values of $P_{\mathrm{s}}$ and $\sigma_{\mathrm{NaCl}}$. The model is subject to uncertainty with regard to the value of DVR hydraulic conductivity $\left(L_{\mathrm{p}}\right)$ and the sum of interstitial hydraulic and oncotic pressure $(\gamma)$. In two prior communications, we have shown that $\gamma$ is $\sim-7 \mathrm{mmHg}$ in the pericapillary interstitium of nonperfused DVR $(6,7)$. As previously explained, a nonzero $J_{\mathrm{v}}$ might be expected to alter $\gamma(7)$. Based on these considerations we have previously determined that $L_{\mathrm{p}}$ of the DVR is at least $1.4 \times 10^{-6} \mathrm{~cm} /(\mathrm{s}-\mathrm{mmHg})($ if $\gamma=-7 \mathrm{mmHg}$ ) but probably does not exceed $3.4 \times 10^{-6} \mathrm{~cm} /(\mathrm{s}-\mathrm{mmHg})(7)$. To account for these uncertainties, the model equations have been solved for the case where $\gamma=-7$ or $7 \mathrm{mmHg}$ and where $L_{\mathrm{p}}$ $=1.4 \times 10^{-6} \mathrm{~cm} /(\mathrm{s}-\mathrm{mmHg})$ or twice that value.

Predictions of the value of $Q_{\mathrm{v}}$ for $L_{\mathrm{p}}=1.4 \times 10^{-6} \mathrm{~cm} /$ (s-mm $\mathrm{mm}$ ) and $\gamma=-7 \mathrm{mmHg}$ are shown in the right panel of Fig. 4 when $P_{\mathrm{s}}$ is assumed to be $60.4 \times 10^{-5} \mathrm{~cm} / \mathrm{s}$ (see above) and $\sigma_{\mathrm{NaCl}}=0.02$ or 0.04 . The shapes of the curves demonstrate the prediction that volume efflux or uptake is nearly complete within $500 \mu \mathrm{m}$ of the perfusion pipette. The data points support this prediction (Fig. 4, left). The very small value of $\sigma_{\mathrm{NaC}}$ required to account for the osmotically induced transcapillary volume flux is also clear.

The effect of the uncertainty is $L_{\mathrm{p}}$ and $\gamma$ on the predicted value of $\sigma_{\mathrm{NaCl}}$ is shown in Table IV. The model predictions are insensitive to the value assumed for $\gamma$. In contrast, doubling the value of $L_{p}$ for the DVR results in about a twofold reduction in the predictions of $\sigma_{\mathrm{NaCl}}$. In any case, the value of $\sigma_{\mathrm{NaCl}}$ for the papillary DVR is unlikely to exceed 0.05 .

The effect of the uncertainty in $L_{\mathrm{p}}$ and $\gamma$ on the predicted value of $P_{\mathrm{s}}$ is shown in Table $\mathrm{V}$. The model predictions are completely insensitive to these uncertainties and yield estimates of $P_{\mathrm{s}}$ indistinguishable from that obtained when $J_{\mathrm{v}}=0$ (group III-161, $P_{\mathrm{s}}=60.4 \times 10^{-5} \mathrm{~cm} / \mathrm{s}$ ).

\section{Discussion}

It has been demonstrated that plasma protein is concentrated during transit of blood from the corticomedullary junction to the papillary tip in descending vasa recta. This observation has been attributed to volume efflux from those capillaries $(3,6)$. Water is transported from the lumen of DVR to the papillary interstitium despite the fact that plasma oncotic pressure exceeds hydraulic pressure in the hydropenic Munich-Wistar rat. Sanjana et al. recognized that a large negative pressure within the papillary interstitium could not explain this observation because water is transported from the papillary interstitium into ascending vasa recta $(3,16,17)$. Based upon this analysis

Table IV. Model Predictions of the Value of $\sigma_{\mathrm{NaCl}}$ of the Papillary Descending Vasa Recta

\begin{tabular}{llll}
\hline \multicolumn{2}{c}{$L_{\mathrm{p}}=1.4 \times 10^{-6} \mathrm{~cm} /(\mathrm{s}-\mathrm{mmHg})$} & $\gamma=-7 \mathrm{mmHg}$ & $\gamma=7 \mathrm{mmHg}$ \\
\hline $\begin{array}{l}\text { Group III-0 } \\
\text { Group III-322 }\end{array} \quad[\mathrm{NaCl}]=0 \mathrm{mM}$ & $0.035 \pm 0.003$ & $0.039 \pm 0.004$ \\
\multicolumn{2}{c}{$L_{\mathrm{p}}=2.8 \times 10^{-6} \mathrm{~cm} /(\mathrm{s}-\mathrm{mmHg})$} & & \\
\hline Group III-0 & {$[\mathrm{NaCl}]=0 \mathrm{mM}$} & $0.017 \pm 0.002$ & $0.021 \pm 0.002$ \\
Group III-322 & {$[\mathrm{NaCl}]=322 \mathrm{mM}$} & $0.017 \pm 0.002$ & $0.013 \pm 0.002$
\end{tabular}

Table V. Model Predictions of the Value of $P_{\mathrm{NaCl}}\left(\times 10^{-5} \mathrm{~cm} / \mathrm{s}\right)$ of the Papillary Descending Vasa Recta

\begin{tabular}{lccc}
\hline \multicolumn{2}{c}{$L_{\mathrm{p}}=1.4 \times 10^{-6} \mathrm{~cm} /(\mathrm{s}-\mathrm{mmHg})$} & $\gamma=-7 \mathrm{mmHg}$ & $\gamma=7 \mathrm{mmHg}$ \\
\hline $\begin{array}{l}\text { Group III-0 } \\
\text { Group III-322 }\end{array} \quad[\mathrm{NaCl}]=0 \mathrm{mM}$ & $67.1 \pm 5.5$ & $66.9 \pm 5.5$ \\
\multicolumn{2}{c}{$L_{\mathrm{p}}=2.8 \times 10^{-6} \mathrm{~cm} /(\mathrm{s}-\mathrm{mmHg})$} & & $65.0 \pm 4.8$ \\
\hline Group III-0 & {$[\mathrm{NaCl}]=0 \mathrm{mM}$} & $66.6 \pm 5.5$ & $66.1 \pm 5.5$ \\
Group III-322 & {$[\mathrm{NaCl}]=322 \mathrm{mM}$} & $65.4 \pm 4.9$ & $65.1 \pm 4.9$ \\
\hline
\end{tabular}

the authors hypothesized the transcapillary small solute gradients generated by the lag in equilibration of DVR plasma with the hypertonic medullary interstitium provides an additional driving force for osmotic water withdrawal from DVR. According to Eq. 1, this requires the reflection coefficient of the DVR wall for either or both $\mathrm{NaCl}$ and urea to be nonzero (3). This hypothesis was supported by our observation that volume efflux from the DVR is abated when corticomedullary small solute gradients are eliminated by the administration of furosemide and saline (6). Thus, the ability of small solute gradients to influence transport of water across the medullary microvasculature had previously been infered from indirect evidence.

The present study provides a definitive test of the "small solute" hypothesis. Papillary DVR were perfused at $10 \mathrm{nl} / \mathrm{min}$ during furosemide diuresis with solutions made isotonic, hypertonic, or hypotonic to the interstitium by adjustment of the perfusate $\mathrm{NaCl}$ concentration. Transcapillary volume flux was determined from the change in concentration of a volume marker (FITC labeled dextran, $2 \times 10^{-6} \mathrm{~mol} \mathrm{wt}$ ) in the perfusate. To measure osmotic equilibration of $\mathrm{NaCl}$ with the papillary interstitium, we also included ${ }^{22} \mathrm{Na}$ in the perfusate. This experimental design permitted direct measurement of the rate of transcapillary water movement to be obtained as the direction of transcapillary $\mathrm{NaCl}$ gradients was altered.

Experimental model. Furosemide and saline diuresis was employed because this protocol eliminates axial $\mathrm{NaCl}$ and urea concentration gradients in the papilla that would otherwise confound interpretation of microperfusion experiments (Table II) $(6,7)$. Experimental manipulation of the magnitude and direction of transcapillary $\mathrm{NaCl}$ gradients was possible because interstitial $\mathrm{NaCl}$ concentration is constant in the papilla during furosemide diuresis. In addition, we have shown that transcapillary volume flux is zero in nonperfused DVR (6) and AVR (7) so that a state of near "filtration equilibrium" exists. In this case, transcapillary driving forces are balanced and the sum of intracapillary hydraulic and oncotic pressure equals that in the papillary interstitium $(\sim-7 \mathrm{mmHg})(6,7)$. It is likely that the state of the papillary interstitium near microperfused capillaries is altered when $J_{v}$ becomes nonzero (7). The value of -7 $\mathrm{mmHg}$ obtained by assuming filtration equilibrium, however, provides a reference point around which theoretical perturbations can be examined (Tables IV and V). It is unlikely that variation of small solute concentrations in microperfused capillaries will markedly alter the concentrations of $\mathrm{NaCl}$ and urea in the pericapillary interstitium provided that the capillary wall and not diffusion through the papillary interstitium represents the limiting resistance to transport of those solutes.

Transmembrane volume flux. When perfusate buffer small 
solute composition was equal to that of the papillary interstitium $(\mathrm{NaCl}$ concentration, $161 \mathrm{mM})$, and perfusate albumin concentration was $5 \mathrm{~g} / \mathrm{dl}$ transcapillary volume flux was zero (group III-161, Fig. 2, Table III), as previously observed (7). When perfusate $\mathrm{NaCl}$ concentration was made $161 \mathrm{mM}$ hypotonic (group III-0) or hypertonic (group III-322) to the papillary interstitium, similar degrees of water movement were induced opposite directions (Fig. 4, Table III). This proves that transcapillary $\mathrm{NaCl}$ concentration gradients are osmotically active across the DVR wall, i.e., $\sigma_{\mathrm{NaCl}}$ is nonzero. When corticomedullary gradients of $\mathrm{NaCl}$ are present in the hydropenic kidney, transcapillary $\mathrm{NaCl}$ concentration gradients are induced as DVR plasma lags in equilibration with the medullary interstitium. This study shows that concomitant volume efflux from DVR can be expected to result.

Diffusive permeability of $\mathrm{DVR}$ to $\mathrm{NaCl}, \mathrm{P}_{\mathrm{s}}$. The data support the notion that there is rapid equilibration of $\mathrm{NaCl}$ with the papillary interstitium. Sodium permeability of the DVR, $P_{\mathbf{s}}$ $\left(60.4 \times 10^{-5} \mathrm{~cm} / \mathrm{s}\right.$, group III-161) is high. Coupling between diffusion and convection is not apparent from the experiments performed in groups III-0 and III-322. In those groups, convective flux of ${ }^{22} \mathrm{Na}$ was in opposite directions but the collectateto-perfusate ${ }^{22} \mathrm{Na}$ concentration ratios were identical (Fig. 3). This is not suprising because diffusion of ${ }^{22} \mathrm{Na}$ from capillary lumen to interstitium was the dominant mode of transport. Determination of $P_{\mathrm{s}}$ from measurements in groups III-0 and III-322 yielded similar estimates of $P_{s}$ (Table V) lending confidence to the values obtained. Furthermore, calculation of $P_{s}$ proved to be insensitive to uncertainties about DVR hydraulic conductivity and papillary interstitial Starling forces.

Marsh and Segel have previously measured sodium permeability for the DVR of hamsters. They obtained a value of 27.6 $\times 10^{-5} \mathrm{~cm} / \mathrm{s}$ (9). Morgan and Berliner obtained a value of 66 $\times 10^{-5} \mathrm{~cm} / \mathrm{s}$ for the permeability of vasa recta to urea in the presence of antidiuretic hormone and $47 \times 10^{-5} \mathrm{~cm} / \mathrm{s}$ in its absence. The majority of their microvessel perfusions were thought to be DVR (18). From those studies and the results of current experiments, it is apparent that the DVR are highly permeable to $\mathrm{NaCl}$ and urea. This is consistent with their role as countercurrent exchangers of those solutes.

Reflection coefficient for $\mathrm{NaCl}$. As previously described with Eq. 8, the osmotic pressure exerted by $\mathrm{NaCl}$ gradients across the DVR wall, is given by (2):

$\sigma_{\mathrm{NaCl}} \Delta \Pi_{\mathrm{s}}=\sigma_{\mathrm{NaCl}} 1.86 R T\left(\Delta C_{\mathrm{s}}\right)$,

the value of $R T$ is $19.33 \mathrm{mmHg} /(\mathrm{mmol} / \mathrm{liter})$ so that a transcapillary gradient of only $10 \mathrm{mmol} /$ liter yields an osmotic pressure gradient of nearly $200 \mathrm{mmHg}$, well in excess of typical Starling forces. We have previously shown that the hydraulic conductivity of the DVR is sufficiently high for Starling forces to induce water movement (7). Those results are only consistent with the present study if the value of $\sigma_{\mathrm{NaC}}$ for the DVR wall is very small. Analysis of the measurements of water efflux and uptake from microperfused DVR in groups III- 0 and III-322 suggest that the value of $\sigma_{\mathrm{NaCl}}$ is indeed less than 0.05 although, due to uncertainty in the value of DVR hydraulic conductivity, a unique value cannot be provided. Consistent with this finding, Curry et al. have determined a value of $\sigma_{\mathrm{NaCl}}$ for capillaries of the frog mesentery to be 0.07 (5). Those microvessels, like the mammalian DVR, have a continuous endothelium.

DVR originate from juxtamedullary efferent arterioles and subsequently undergo a gradual change in ultrastructure as they sequentially penetrate the outer and inner medulla of the kidney. Smooth muscle is replaced by pericytes and the media eventually disappears $(19,20)$. They then continue with a nonfenestrated endothelium (21). Prior to the origination of AVR. the capillary endothelium develops fenestrations which appear to be bridged by 40 - $\AA$-thick diaphrams (22). Thus, the fenestrated endothelium of AVR is also characteristic of DVR near their terminus. DVR in this study were perfused near the papillary tip. Consequently, the transport properties measured are likely to be representative of the heterogenous endothelial structure of papillary DVR. It cannot be assumed that DVR segments in the outer medulla, especially near the origin from efferent arterioles, have similar properties.

Summary. Due to the presence of corticomedullary gradients of $\mathrm{NaCl}$ and urea in the medulla of the kidney blood descends into a region of increasing osmolality. $\mathrm{NaCl}$ and urea equilibrate with DVR plasma by diffusing across the DVR wall, a process which generates transcapillary gradients of these small solutes. It is generally accepted that water movement across capillaries is driven by transmural gradients of hydraulic and oncotic pressure. It has been hypothesized that DVR are capillaries which behave in a unique way such that transcapillary small solute gradients generated by the lag in equilibration of plasma and medullary interstitium also affect water movement. This hypothesis has been derived from the observation that water is transported from the DVR lumen to the papillary interstitium despite Starling forces that appear to favor water uptake (3). Kedem and Katchalsky have provided a general theory which accounts for water movement across biological membranes (4). In order for a solute to generate water movement across a membrane, a difference in its chemical potential (concentration) must exist and the membrane must have a nonzero reflection coefficient to the solute in question (Eqs. 1 and 8 ). Therefore, if small solutes ( $\mathrm{NaCl}$ or urea) are capable of providing a thermodynamic driving force for osmotic withdrawal of water from the papillary DVR the reflection coefficient of the DVR to either or both of these solutes must be nonzero.

The current experiments prove that transcapillary gradients of $\mathrm{NaCl}$ do indeed influence water movement across DVR. When DVR were perfused with a buffer containing a low $\mathrm{NaCl}$ concentration, water efflux occurred. When DVR were perfused with a buffer containing a high $\mathrm{NaCl}$ concentration, volume influx occurred (Fig. 5). By simultaneously measuring both the rate at which $\mathrm{NaCl}$ equilibrated across perfused DVR and the magnitude of transcapillary volume flux, it was possible to apply the Kedem Katchalsky equation to obtain an upper boundary on the value of the reflection coefficient of the DVR to $\mathrm{NaCl}\left(\sigma_{\mathrm{NAC}}\right.$, Table IV) and estimate the permeability of the DVR to $\mathrm{NaCl}\left(P_{s}\right.$, Table V). Those results demonstrate that the papillary DVR have a high permeability to $\mathrm{NaCl}$ supporting the notion that they are one arm of an efficient $\mathrm{NaCl}$ countercurrent exchanger. $\sigma_{\mathrm{NaCl}}$ is found to be nonzero but $<0.05$. This demonstrates that osmotic driving forces generated by small solutes can successfully oppose Starling forces even though the reflection coefficient to the solutes is small.

\section{Acknowledgments}

The assistance of Malgorzata Sudol with the fluorescein microassay is gratefully acknowledged. 
This work was supported by National Institutes of Health grant R29 DK424495-01, a Bioengineering Research Grant from the Whitaker Foundation, a Young Investigator Award from the National Kidney Foundation, and a Special Investigatorship from the Pennsylvania affiliate of the American Heart Association.

\section{References}

1. Stephenson, J. L. 1972. Central core model of the renal counterflow system. Kidney Int. 2:85-94.

2. Pallone, T. L., T. I. Morgenthaler, and W. M. Deen. 1984. Analysis of microvascular water and solute exchange in the renal medulla. Am. J. Physiol. 247:F303-315.

3. Sanjana, V. M., P. A. Johnston, C. R. Robertson, and R. L. Jamison. 1976. An examination of the transcapillary water flux in the renal medulla. Am. J. Physiol. 231:313-318.

4. Kedem, O., and A. Katchalsky. 1958. Thermodynamic analysis of the permeability of biological membranes to nonelectrolytes. Biochim. Biophys. Acta. 27:229-246.

5. Curry, F. E., J. C. Mason, and C. C. Michel. 1976. Osmotic reflection coefficients of capillary walls to low molecular weight hydrophilic solutes measured in single perfused capillaries of the frog mesentery. J. Physiol. (Lond.) 261:319-336.

6. Pallone, T. L., Y. Yagil, and R. L. Jamison. 1989. Effect of small-solute gradients on transcapillary fluid movement in renal inner medulla. Am. J. Physiol. 257:F547-F553.

7. Pallone, T. L., J. Work, and R. L. Jamison. 1990. The resistance of the descending vasa recta to the transport of water. Am. J. Physiol. 259:F688-F697.

8. Pallone, T. L., and R. L. Jamison. 1988. Effect of ureteral excision on inner medullary solute concentration in rats. Am. J. Physiol. 255:F1225-F1229.

9. Marsh, D. J., and L. A. Segel. 1971. Analysis of countercurrent diffusion exchange in blood vessels of the renal medulla. Am. J. Physiol. 221:817-828.
10. Gutsche, H.-U., R. Muller-Suur, U. Hegel, K. Hierholzer, and S. Luderitz. 1975. A new method for intratubular blockade in micropuncture experiments. Pfluegers Arch. Eur. J. Physiol. 354:197-202.

11. Vurek, G. G., and M. A. Knepper. 1982. A colorimeter for measurement of picomole quantities of urea. Kidney Int. 21:656-658.

12. Ramsay, R. A., and R. H. Brown. 1955. Simplified apparatus and procedure for freezing point determination upon small volumes of fluid. J. Sci. Instrum. 32:372-375.

13. Landis, E. M., and J. R. Pappenheimer. 1963. Exchange of substances through the capillary wall. In Handbook of Physiology. American Physiology Society, Washington, DC. 962-1034.

14. Patlack, C. S., D. A. Goldstein, and J. F. Hoffman. 1963. The flow of solute and solvent across a two-membrane system. J. Theor. Biol. 5:426-442.

15. Gear, C. W. 1971. Numerical Initial Value Problems in Ordinary Differential Equations. Prentice-Hall, Englewood Cliffs, NJ. 253 pp.

16. Sanjana, V. M., P. A. Johnston, J. L. Troy, W. M. Deen, C. R. Robertson, B. M. Brenner, and R. L. Jamison. 1975. Hydraulic and oncotic pressure measurements in the inner medulla of the mammalian kidney. Am J. Physiol. 228:19211926.

17. Zimmerhackl, B., C. R. Robertson, and R. L. Jamison. 1985. Fluid uptake in the renal papilla by vasa recta estimated by two methods simultaneously. $\mathrm{Am}$. J. Physiol. 248:F347-F353.

18. Morgan, T., and R. W. Berliner. 1968. Permeability of the loop of Henle, vasa recta and collecting duct to water, urea, and sodium. Am. J. Physiol. 215:108-115.

19. Jamison, R. L., and W. Kriz. 1982. Urinary Concentrating Mechanism. Structure and Function. Oxford University Press, New York. 259-271.

20. Pallone, T. L., C. Robertson, and R. L. Jamison. 1990. Renal Medullary Microcirculation. Physiol. Rev. 70:885-920.

21. Schwartz, M. M., M. J. Karnovsky, and M. A. Venkatachalam. 1976. Ultrastructural differences between rat inner medullary descending and ascending vasa recta. Lab. Invest. 35:161-170.

22. Maul, G. G. 1971. Structure and formation of pores in fenestrated capillaries. J. Ultrastruct. Res. 36:768-782. 